(C) 2017, Elsevier. Licensed under the Creative Commons Attribution-NonCommercialNoDerivatives 4.0 International, http://creativecommons.org/licenses/by-nc-nd/4.0/

\title{
Characterisation of the porcine eyeball as an in-vitro model for dry eye
}

Francesco Menduni ${ }^{a}, \mathrm{~b}$, Leon N. Daviesa ${ }^{\mathrm{a}}$, D Madrid-Costa ${ }^{\mathrm{b}}$, Antonio Fratini ${ }^{\mathrm{a}}$, James S. Wolffsohn ${ }^{\mathrm{a}}$

a School of Life and Health Science, Aston University, Birmingham, UK

b Optics and Optometry Department, Complutense University of Madrid, Madrid, Spain

\section{HIGHLIGHTS:}

- The anatomy of the porcine eye has been described in detail.

- Porcine eyes may be a useful tool in contact lens research.

- Commercial contact lens may not fit well on a porcine eye.

Porcine eyes represent a reliable/high quality tissue source for studying dry eye.

\section{ABSTRACT}

Purpose: To characterise the anatomical parameters of the porcine eye for potentially using it as a laboratory model of dry eye.

Methods: Anterior chamber depth and angle, corneal curvature, shortest and longest diameter, endothelial cells density, and pachymetry were measured in sixty freshly enucleated porcine eyeballs.

Results: Corneal steepest meridian was $7.85 \pm 0.32 \mathrm{~mm}$, corneal flattest meridian was $8.28 \pm$ $0.32 \mathrm{~mm}$, shortest corneal diameter was $12.69 \pm 0.58 \mathrm{~mm}$, longest corneal diameter was 14.88 $\pm 0.66 \mathrm{~mm}$ and central corneal ultrasonic pachymetry was $1009 \pm 1 \mu \mathrm{m}$. Anterior chamber angle was $28.83 \pm 4.16 \mathrm{deg}$, anterior chamber depth was $1.77 \pm 0.27 \mathrm{~mm}$, and central corneal thickness measured using OCT was $1248 \pm 144 \mu \mathrm{m}$. Corneal endothelial cells density was 3250 \pm 172 cells $/ \mathrm{mm}^{2}$.

Conclusions: Combining different clinical techniques produced a pool of reproducible data on the porcine eye anatomy, which can be used by researchers to assess the viability of using the porcine eye as an in-vitro/ex-vivo model for dry eye. Due to the similar morphology with the human eye, porcine eyeballs may represent a useful and cost effective model to individually study important key factors in the development of dry eye, such as environmental and mechanical stresses. 


\section{KEYWORDS:}

Porcine eye; In vitro; Ex vivo; Dry Eye; Confocal microscopy; Optical Coherence Tomography.

\section{INTRODUCTION}

Advances in biomedical technologies are constantly improving reliability and standardisation of in-vitro/ex-vivo animal models as a replacement for the use of living laboratory animals [1]. In dry eye research, these models may emerge as consistent platforms to effectively study the causative factors of this disease, as well as to extensively evaluate the effect of new treatments. Indeed, due to the possibility of efficiently manipulating parameters like temperature, humidity and blinking rate, different severities of dry eye can be investigated both at macroscopic level (e.g. fluorescein/lissamine green staining) [2], and at cellular/ultrastructural level (e.g. live/dead staining, SEM, TEM) [3].

While the mouse remains the most attractive in vivo animal model of dry eye due to the availability of transgenic strains and specific reagents [4], recently the porcine eye has been extensively used as an ex-vivo animal model due to its proposed similar morphology and ter film to the human eye [5-11]. In particular, Choy and colleagues developed a system in which different levels of severity of dry eye can be mimicked manipulating "blinking rate" and "tear volume" [2].

Moreover, porcine lacrimal and Meibomian glands have been shown to be similar to humans [12], and the recently sequenced genome of Suf scrofa indicates that pigs are genetically more similar to humans than mice, further stressing the validity of this model [13]. In 1997, Bartholomew and colleagues analysed 25 porcine globes using ultrasound biomicroscopy [14]. Since then, further studies have examined some porcine eye parameters, but, as summarised in Table 1, their sample size and the parameters investigated have been limited [6, 7, 15-17]. In addition, in these studies eyes have generally been transported on ice prior to measurement, which may affect the structural and physiological integrity of the sample. Therefore, a source of reproducible data concerning the parameters of the porcine eye, including corneal topography and confocal microscopy, is required.

\begin{tabular}{ccccc}
\hline Author/s & $\begin{array}{c}\text { No. of } \\
\text { eyes }\end{array}$ & $\begin{array}{c}\text { Parameters } \\
\text { evaluated }\end{array}$ & Method & Relevant results \\
\hline
\end{tabular}




\begin{tabular}{|c|c|c|c|c|}
\hline $\begin{array}{l}\text { Bartholomew, } \\
\text { L. R., et al. } \\
(1997)^{14}\end{array}$ & 25 & $\begin{array}{l}\text { Anterior chamber } \\
\text { measurements } \\
\text { Globe diameters } \\
\text { Corneal diameters }\end{array}$ & $\begin{array}{c}\text { Ultrasound } \\
\text { biomicroscopy scanner }\end{array}$ & $\begin{array}{c}\text { ACD: } \\
2.21 \mathrm{~mm} \\
\\
\text { HCD: } \\
16.61 \mathrm{~mm} \\
\text { VCD: } \\
14.00 \mathrm{~mm}\end{array}$ \\
\hline $\begin{array}{l}\text { Asejczyk- } \\
\text { Widlicka, M., } \\
\text { et al. }(2008)^{15}\end{array}$ & $\begin{array}{l}12 \\
12\end{array}$ & $\begin{array}{c}\text { Corneal and } \\
\text { anterior chamber } \\
\text { measurements } \\
\text { Sclera thickness } \\
\end{array}$ & $\begin{array}{c}\text { Time domain } \\
\text { Optical Coherence } \\
\text { Tomographer } \\
\text { (Visante OCT system, } \\
\text { Carl Zeiss Meditec, Inc) }\end{array}$ & $\begin{array}{c}\text { CCT: } \\
0.96 \pm 0.05 \mathrm{~mm} \\
\text { ACD: } \\
2.13 \pm 0.22 \mathrm{~mm} \\
\end{array}$ \\
\hline $\begin{array}{l}\text { Sanchez, I., et } \\
\text { al. }(2011){ }^{16}\end{array}$ & 5 & $\begin{array}{c}\text { Keratometric } \\
\text { power } \\
\text { Corneal Astigmatic } \\
\text { power } \\
\text { Ultrasonic } \\
\text { pachymetry } \\
\text { Slit-scan } \\
\text { pachymetry } \\
\text { Corneal diameters }\end{array}$ & $\begin{array}{c}\text { Portable } \\
\text { autokeratometer } \\
\text { (ARK-30 Nidek, } \\
\text { Fremont, CA, USA) } \\
\text { Manual keratometer } \\
\text { (OM-4 Topcon, Tokio, } \\
\text { Japan) } \\
\text { Ultrasound pachymeter } \\
\text { (Sonogage Corneo-Gage } \\
\text { Plus, Renaissance } \\
\text { Parkway, Cleveland, } \\
\text { OH, USA) } \\
\text { Corneal topographer } \\
\text { (Orbscan® II, Bausch } \\
\text { and Lomb, Rochester, } \\
\text { NY, USA) }\end{array}$ & $\begin{array}{c}\text { Automatic } \\
\text { Keratometry } \\
\text { Ks: } 41.19 \pm 1.76 \mathrm{D} \\
\text { Kf: } 38.83 \pm 2.89 \mathrm{D} \\
\Delta \mathrm{K}: 2.36 \pm 1.70 \mathrm{D} \\
\\
\text { HCD: } \\
14.3 \pm 0.25 \mathrm{~mm} \\
\text { VCD: } \\
12.00 \pm 0 \mathrm{~mm} \\
\text { Central corneal } \\
\text { pachymetry: } \\
877 \pm 13.58 \mu \mathrm{m} \\
\\
\text { Slit-scan } \\
\text { pachymetry: } \\
906.2 \pm 15.30 \mu \mathrm{m}\end{array}$ \\
\hline $\begin{array}{l}\text { Heichel, J., et } \\
\text { al. }(2016){ }^{17}\end{array}$ & 16 & 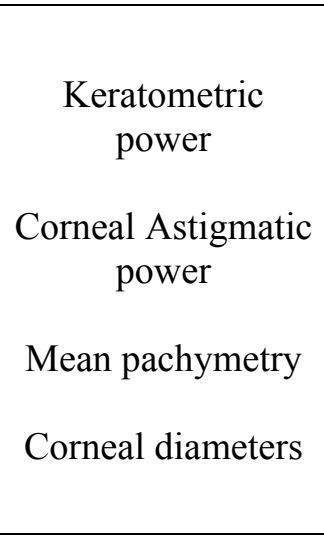 & $\begin{array}{c}\text { Corneal topographer } \\
\text { (Orbscan }{ }^{\circledR} \text { IIz, Bausch } \\
\text { and Lomb, Rochester, } \\
\text { NY, USA) }\end{array}$ & $\begin{array}{c}\text { Automatic } \\
\text { Keratometry } \\
\text { Ks: } 39.6 \pm 0.89 \mathrm{D} \\
\text { Kf: } 38.5 \pm 0.92 \mathrm{D} \\
\Delta \mathrm{K}: 1.10 \pm 0.78 \mathrm{D} \\
\\
\text { Central corneal } \\
\text { pachymetry: } \\
832.6 \pm 40.18 \mu \mathrm{m} \\
\\
\text { Corneal diameter: } \\
13.81 \pm 0.83 \mathrm{~mm}\end{array}$ \\
\hline
\end{tabular}

Table 1: Key aspects of previous studies analysing the porcine eyeball parameters. ACD: Anterior chamber depth; HCD: Horizontal corneal diameter; VCD: Vertical corneal diameter; CCT: Central corneal thickness; Ks: Steepest meridian; Kf: Flattest meridian.

The aim of this study was to provide detailed anatomical parameters of the porcine eye, to help vision scientists to effectively use the pig eye as a biomedical model in the applied ophthalmic research such as in dry eye. 


\section{MATERIALS AND METHODS}

Sixty porcine eyes were enucleated at a local abattoir around 12:00 noon and transferred to the laboratory in a transport solution at $4^{\circ} \mathrm{C}$. The transport solution consisted of Dulbecco's Modified Eagle's Medium (DMEM; Lonza, Berkshire, UK), supplemented with 1\% penicillin $(10,000$ units $/ \mathrm{ml})$ and streptomycin $(10,000 \mathrm{mg} / \mathrm{ml}), 1 \% \mathrm{v} / \mathrm{v}$ L-glutamine (Lonza, Berkshire, UK), 10\% Foetal Bovine Serum (FBS; Sigma-Aldrich, UK) and 20\% w/v Dextran $\left(\mathrm{M}_{\mathrm{w}} \sim 250 \mathrm{kDa}\right.$, Sigma-Aldrich, UK). The latter was added to minimise corneal swelling post enucleation. Animals were white domestic pigs aged between 12 to 25 weeks, which did not undertake any scalding process. To avoid tissue deterioration, examinations were performed within 6 hours after enucleation.

Central corneal curvature was measured with E300 Corneal Topographer (Medmont, Melbourne, Australia). Corneal thickness (central and at 5mm and 9mm eccentricity), anterior chamber depth and angle were measured with a Visante OCT system (Carl Zeiss Meditec, Inc, Oberkochen, Germany). Corneal thickness was also evaluated using an ultrasonic pachymeter (UP-1000, Nidek, Gamagori, Aichi, Japan). Eyeballs images were taken with a digital slitlamp (CSO, Firenze, Italy) and both the longest and shortest corneal diameter were evaluated using ImageJ software (https://imagej.nih.gov/ij/). Corneal endothelial cells are high specialised cells, which do not divide in vivo. ECD is, therefore, a commonly reported indicator of corneal health, as values below $~ 500$ lead to oedema, corneal clouding and eventually vision loss in humans [18].

Endothelial cell density (ECD) was obtained using a scanning slit confocal microscope (ConfoScan 3, Nidek Technologies, Padova, Italy). Different eyeball holders were specially designed to securely position samples during imaging and measurements without distorting the natural structure. To prevent dehydration, samples were regularly irrigated with saline solution during the experimental procedure. Experiments were performed at room temperature.

Statistical analysis was performed using Matlab software (The Mathworks, Inc., Natick, MA). Kolmogrov- Smirnov test was used to determine whether the data were normally distributed. Data were found to be normally distributed $(p>0.05)$.

\section{RESULTS}

\section{Corneal curvature}

Corneal curvature data are illustrated in Figure 1. 
[Please place Figure 1 here]

The average corneal steepest and flattest meridian were $7.85 \pm 0.32 \mathrm{~mm}$ and $8.28 \pm 0.32 \mathrm{~mm}$, respectively, with associated shape factor (p-value) of $0.38 \pm 0.25$ and $0.51 \pm 0.30$ [19], and a mean curvature difference $(\Delta \mathrm{K})$ of $0.43 \pm 0.18 \mathrm{~mm}$.

\section{Corneal thickness}

Central corneal thickness, measured with the Visante OCT system and the ultrasonic pachymeter, were $1009 \pm 1 \mu \mathrm{m}$ and $1248 \pm 144 \mu \mathrm{m}$, respectively. OCT data distribution is presented in Figure 2.

[Please place Figure 2 here]

The porcine corneal thickness was relatively constant in the centre and slightly thickened towards the limbus. In particular, the corneal thickness was found to be $2 \%$ and $8 \%$ thicker at $5 \mathrm{~mm}$ and $9 \mathrm{~mm}$ from the centre, respectively, in a sample of twenty eyeballs that guaranteed the best alignment with the instrument (Figure 3).

[Please place Figure 3 here]

\section{Anterior chamber angle and depth}

Anterior chamber depth was measured from the posterior corneal surface to the anterior lens, Figure 4.

[Please place Figure 4 here]

Data distributions relative to anterior chamber angle and depth are shown in Figure 5.

[Please place Figure 5 here]

The average anterior chamber angle was $28.83 \pm 4.16 \mathrm{deg}$, while the mean anterior chamber depth was $1.72 \pm 0.26 \mathrm{~mm}$. It has to be noted that the OCT obtains the geometrical path measure dividing the optical path length by the refractive index value of 1.376. Taking into account that 
the anterior chamber is filled with aqueous humour, whose refractive index is 1.333 , correcting for this discrepancy the mean anterior chamber depth was $1.77 \pm 0.27 \mathrm{~mm}$ [20].

\section{Corneal diameters}

Data related with corneal diameters are reported in Figure 6.

[Please place Figure 6 here]

The average shortest corneal diameter was $12.69 \pm 0.58 \mathrm{~mm}$, while the mean longest corneal diameter was $14.88 \pm 0.66 \mathrm{~mm}$.

\section{Endothelial cell density (ECD)}

A small sample of ten porcine eyes that guaranteed the best corneal transparency were used for the determination of ECD. The average ECD was $3250 \pm 172$ cells $/ \mathrm{mm}^{2}$, and an exemplary confocal image of the porcine corneal endothelial layer is shown in Figure 7.

[Please place Figure 7 here]

\section{DISCUSSION}

Ex-vivo eye models provide economic and logistical advantages for animal alternatives, as they allow faster safety and risk assessment of chemicals/pharmaceuticals, with a potential greater predictive relevance for human and environmental safety compared to cumbersome animalbased approaches [21]. In vision science research, the porcine eye is one of the most commonly used models, as its morphology has been widely investigated $[22,23]$. However, experimental evaluations of the main parameters of the porcine eyeball are scarce in the academic literature, especially with regard to corneal topography and endothelial imaging. This study investigated several anatomical parameters of the porcine eye, combining optical mapping, confocal microscopy, ultrasonic pachymetry and OCT.

The viability of using optical mapping systems such as the Medmont E300 Corneal Topographer was assessed in evaluating porcine corneal topography ex-vivo. An average corneal steepest and flattest meridian of $7.85 \pm 0.32 \mathrm{~mm}$ and $8.28 \pm 0.32 \mathrm{~mm}$ were respectively found, with associated eccentricity $(\varepsilon=\sqrt{1-p})$ of $0.79 \pm 0.17$ and $0.70 \pm 0.20$, and with a mean $\Delta \mathrm{K}$ of $0.43 \pm 0.18 \mathrm{~mm}$. These values are slightly smaller than those reported by Sanchez et al. $(8.19 \mathrm{~mm}$ and $8.69 \mathrm{~mm}, \Delta \mathrm{K}=0.50 \mathrm{~mm})$ [16] and Heichel et al. $(8.52 \mathrm{~mm}$ and $8.77 \mathrm{~mm}$, 
$\Delta \mathrm{K}=0.25 \mathrm{~mm}$ ) [17], but more closely centred in the range of human anterior corneal curvature (7.06 to $8.66 \mathrm{~mm}$ ) [24]. This is the first time the shape factor (or rate of flattening of the cornea from the centre to the periphery) of porcine eyes has been reported. Being greater than humans $(0.41 \pm 0.11)$, it reflects that the porcine corneal surface is flatter, but both corneal geometries are elliptical in shape [19]. These interesting findings suggest that porcine eyes may also be used as a valuable tool in the research and development on new contact lens materials.

With regards to corneal thickness, it is worth noting that the porcine cornea is characterised by a thicker epithelium and stroma than the human, and lacks Bowman's layer [16]. Using ultrasonic pachymetry and OCT, a mean central corneal thickness of $1009 \pm 1 \mu \mathrm{m}$ and $1248 \pm$ $144 \mu \mathrm{m}$ were respectively obtained. The former value is comparable to both the one obtained ex-vivo by Jay et al. [25] using laser scanning microscopy $(1013 \pm 10 \mu \mathrm{m})$, and the one obtained ex-vivo by Asejczyk-Widlicka et al. [15] using a Visante OCT $(960 \pm 50 \mu \mathrm{m})$. In addition, all in-vitro/ex-vivo study findings are considerably higher than in vivo findings (666 $\mu \mathrm{m})$ [26]. This difference may be related with the different ages and types of pig used, together with potential corneal swelling occurring due to the time after enucleation ex-vivo measurements are taken. The corneal thickness only increased slightly in the periphery $(1.02 \mathrm{x}$ at $5 \mathrm{~mm}$ eccentricity and $1.08 \mathrm{x}$ at $9 \mathrm{~mm}$ eccentricity) so was more similar to the human peripheral cornea [27].

Furthermore, anterior chamber OCT was used to measure anterior chamber angle and depth, revealing an average anterior chamber angle of $28.83 \pm 4.16 \mathrm{deg}$, and a mean (refractive index corrected) anterior chamber depth of $1.77 \pm 0.27 \mathrm{~mm}$. These values are smaller than the ones reported in previous studies [14,15], which may be accounted for by the mounting or transportation methods.

Corneal diameters were digital assessed using ImageJ software. The mean shortest and longest diameter of $12.69 \mathrm{~mm}$ and $14.88 \mathrm{~mm}$ found in this study are in accordance with previous findings in vivo (12.4 $\mathrm{mm}$ and $14.9 \mathrm{~mm}$, respectively) and ex-vivo (14.00 $\mathrm{mm}$ and $16.61 \mathrm{~mm}$, respectively) $[14,26]$. These data outline the asymmetrically oval shape of the porcine cornea, also indicating that standard diameter commercial contact lenses, which have a diameter of approximately $14 \mathrm{~mm}$, would not fit well on a porcine eye.

Finally, a scanning slit confocal system (ConfoScan3, Nidek Technologies, Padova, Italy) was used to evaluate porcine ECD ex-vivo. A mean ECD of $3250 \pm 172 \mathrm{cell} / \mathrm{mm}^{2}$ was found, which is lower than the ones reported in previous studies $\left(4411 \pm 280 \mathrm{cell} / \mathrm{mm}^{2}\right)[26,27]$. The discrepancy may be due to the different technique used, especially because ConfoScan 3 data on porcine eyes has not been found in the literature. The findings of this study are, however, 
within the human normal range $\left(2496.9\right.$ - $\left.4049.5 \mathrm{cell} / \mathrm{mm}^{2}\right)$ assessed using scanning slit confocal systems [30].

The differences between the porcine eye data obtained in this study and corresponding human anterior segment parameters [24, 27, 31-34] are summarised in Table 2.

\begin{tabular}{ccc}
\hline Parameter & Porcine eye & Human eye \\
\hline Corneal steepest meridian & $7.85 \mathrm{~mm}$ & $7.65 \mathrm{~mm}^{19}$ \\
\hline Corneal flattest meridian & $8.28 \mathrm{~mm}$ & $7.79 \mathrm{~mm}^{19}$ \\
\hline Corneal astigmatism $(\Delta \mathrm{K})$ & $0.43 \mathrm{~mm}$ & $0.14 \mathrm{~mm}^{19}$ \\
\hline Central corneal pachymetry & $1009 \mu \mathrm{m}$ & $523 \mu \mathrm{m}^{27}$ \\
\hline Peripheral corneal thickness $(7-9 \mathrm{~mm})$ & $1240 \mu \mathrm{m}$ & $564 \mu \mathrm{m}^{27}$ \\
\hline Anterior chamber depth $(\mathrm{OCT})$ & $1.77 \mathrm{~mm}$ & $3.11 \mathrm{~mm}^{29}$ \\
\hline Anterior chamber angle $(\mathrm{OCT})$ & $28.83 \mathrm{deg}$ & $38.1 \mathrm{deg}^{29}$ \\
\hline Shortest corneal diameter & $12.69 \mathrm{~mm}$ & $11.71 \mathrm{~mm}^{23,31,32}$ \\
\hline Longest corneal diameter & $14.88 \mathrm{~mm}$ & $12.00 \mathrm{~mm}^{23,31,32}$ \\
\hline Endothelial cell density $(\mathrm{ECD})$ & $3250 \mathrm{cell} / \mathrm{mm}^{2}$ & $2496.9-4049.5 \mathrm{cell} / \mathrm{mm}^{22}$ \\
\hline
\end{tabular}

Table 2: Comparison of mean porcine eye parameters obtained in this study and estimated average human eye parameters according to the scientific literature.

Therefore, due to the similarities with the human eye, the porcine eye can be a more valuable in-vitro model of dry eye compared to mouse or rabbit eyes, allowing reproducible studies on contact lenses and solution cytotoxicity.

\section{CONCLUSIONS}

The cost and availability of high quality human donor eyes are obstacles to vision science research. Porcine eyes represent a reliable and high quality tissue source with similar glands producing the tear film that may be combined with bioengineering technologies to provide new useful tools and models in applied ophthalmic research, in particular in dry eye research [9, 35]. The findings of this study represent a further source of reproducible data that should be considered when using porcine eyes as ex-vivo model for experimental research.

\section{CONFLICT OF INTEREST:}

None.

\section{ACKNOWLEDGEMENTS}

The authors gratefully acknowledge the abattoir C.H. Rowley Ltd., and in particular Mr Simon Rowley, for the constant supply of porcine eyes, which made this study possible. Moreover, 
the authors wish to thank Tugce Ipek and Andrea Vitale for the support and assistance during the experiments.

This project has received funding from the European Union's Horizon 2020 research and innovation programme under the Marie Skłodowska-Curie grant agreement No 642760. 


\section{REFERENCES}

[1] Shafaie S, Hutter V, Cook MT, Brown MB, Chau DYS. In Vitro Cell Models for Ophthalmic Drug Development Applications. Bioresearch Open Access. 2016;5.

[2] Choy EPY, Cho P, Benzie IFF, Choy CKM, To TSS. A novel porcine dry eye model system (pDEM) with simulated lacrimation/blinking system: Preliminary findings on system variability and effect of corneal drying. Current Eye Research. 2004;28:319-25.

[3] Zhao B, Cooper LJ, Brahma A, MacNeil S, Rimmer S, Fullwood NJ. Development of a three-dimensional organ culture model for corneal wound healing and corneal transplantation. Investigative ophthalmology \& visual science. 2006;47:2840-6.

[4] Beyazyıldız E, Acar U, Sobacı G. Animal Models of Dry Eye Syndrome for Stem Cell Based Therapies. INTERNATIONAL ADVISORY BOARD. 2012:49.

[5] Fyffe JG, Neal TA, Butler WP, Johnson TE. The ex vivo pig eye as a replacement model for laser safety testing. Comparative Medicine. 2005;55:503-9.

[6] Ruiz-Ederra J, Garcia M, Hernandez M, Urcola H, Hernandez-Barbachana E, Araiz J, et al. The pig eye as a novel model of glaucoma. Experimental eye research. 2005;81:561-9.

[7] Wong KH, Koopmans SA, Terwee T, Kooijman AC. Changes in spherical aberration after lens refilling with a silicone oil. Investigative ophthalmology \& visual science. 2007;48:12617.

[8] Fernandez-Bueno I, Pastor JC, Gayoso MJ, Alcalde I, Garcia MT. Muller and macrophagelike cell interactions in an organotypic culture of porcine neuroretina. Molecular vision. 2008;14:2148-56.

[9] Loewen RT, Roy P, Park DB, Jensen A, Scott G, Cohen-Karni D, et al. A Porcine Anterior Segment Perfusion and Transduction Model With Direct Visualization of the Trabecular Meshwork. Investigative ophthalmology \& visual science. 2016;57:1338-44.

[10] Chan KY, Cho P, Boost M. Corneal epithelial cell viability of an ex vivo porcine eye model. Clin Exp Optom. 2014;97:337-40.

[11] Schmidt TA, Sullivan DA, Knop E, Richards SM, Knop N, Liu S, et al. Transcription, translation, and function of lubricin, a boundary lubricant, at the ocular surface. JAMA Ophthalmol. 2013;131:766-76.

[12] Henker R, Scholz M, Gaffling S, Asano N, Hampel U, Garreis F, et al. Morphological features of the porcine lacrimal gland and its compatibility for human lacrimal gland xenografting. PloS one. 2013;8:e74046. 
[13] Groenen MA, Archibald AL, Uenishi H, Tuggle CK, Takeuchi Y, Rothschild MF, et al. Analyses of pig genomes provide insight into porcine demography and evolution. Nature. 2012;491:393-8.

[14] Bartholomew LR, Pang DX, Sam DA, Cavender JC. Ultrasound biomicroscopy of globes from young adult pigs. Am J Vet Res. 1997;58:942-8.

[15] Asejczyk-Widlicka M, Schachar RA, Pierscionek BK. Optical coherence tomography measurements of the fresh porcine eye and response of the outer coats of the eye to volume increase. Journal of Biomedical Optics. 2008;13:024002--6.

[16] Sanchez I, Martin R, Ussa F, Fernandez-Bueno I. The parameters of the porcine eyeball. Graefe's archive for clinical and experimental ophthalmology = Albrecht von Graefes Archiv fur klinische und experimentelle Ophthalmologie. 2011;249:475-82.

[17] Heichel J, Wilhelm F, Kunert KS, Hammer T. Topographic Findings of the Porcine Cornea. Med Hypothesis Discov Innov Ophthalmol. 2016;5:125-31.

[18] Engelmann K, Bednarz J, Valtink M. Prospects for endothelial transplantation. Experimental eye research. 2004;78:573-8.

[19] Benes P, Synek S, Petrova S. Corneal shape and eccentricity in population. Coll Antropol. 2013;37 Suppl 1:117-20.

[20] Podoleanu A, Charalambous I, Plesea L, Dogariu A, Rosen R. Correction of distortions in optical coherence tomography imaging of the eye. Phys Med Biol. 2004;49:1277-94.

[21] Doke SK, Dhawale SC. Alternatives to animal testing: A review. Saudi Pharm J. 2015;23:223-9.

[22] van Vreeswijk H, Pameyer JH. Inducing cataract in postmortem pig eyes for cataract surgery training purposes. Journal of cataract and refractive surgery. 1998;24:17-8.

[23] Shentu X, Tang X, Ye P, Yao K. Combined microwave energy and fixative agent for cataract induction in pig eyes. Journal of cataract and refractive surgery. 2009;35:1150-5.

[24] Mashige K. A review of corneal diameter, curvature and thickness values and influencing factors. The South African Optometrist. 2013;72.

[25] Jay L, Brocas A, Singh K, Kieffer JC, Brunette I, Ozaki T. Determination of porcine corneal layers with high spatial resolution by simultaneous second and third harmonic generation microscopy. Opt Express. 2008;16:16284-93.

[26] Faber C, Scherfig E, Prause JU, Sorensen KE. Corneal thickness in pigs measured by ultrasound pachymetry in vivo. Scandinavian Journal of Laboratory Animal Science. 2008;35:39-43.

[27] Prospero Ponce CM, Rocha KM, Smith SD, Krueger RR. Central and peripheral corneal thickness measured with optical coherence tomography, Scheimpflug imaging, and ultrasound 
pachymetry in normal, keratoconus-suspect, and post-laser in situ keratomileusis eyes. Journal of cataract and refractive surgery. 2009;35:1055-62.

[28] Schroeter J, Ruggeri A, Thieme H, Meltendorf C. Impact of temporary hyperthermia on corneal endothelial cell survival during organ culture preservation. Graefes Archive for Clinical and Experimental Ophthalmology. 2015;253:753-8.

[29] Kim SY, Yang J, Lee YC. Safety of moxifloxacin and voriconazole in corneal storage media on porcine corneal endothelial cells. J Ocul Pharmacol Ther. 2010;26:315-8.

[30] Bourne WM. Biology of the corneal endothelium in health and disease. Eye (Lond). 2003;17:912-8.

[31] Nemeth G, Vajas A, Tsorbatzoglou A, Kolozsvari B, Modis L, Jr., Berta A. Assessment and reproducibility of anterior chamber depth measurement with anterior segment optical coherence tomography compared with immersion ultrasonography. Journal of cataract and refractive surgery. 2007;33:443-7.

[32] Leung CK, Li H, Weinreb RN, Liu J, Cheung CY, Lai RY, et al. Anterior chamber angle measurement with anterior segment optical coherence tomography: a comparison between slit lamp OCT and Visante OCT. Investigative ophthalmology \& visual science. 2008;49:3469-74. [33] Rufer F, Schroder A, Erb C. White-to-white corneal diameter: normal values in healthy humans obtained with the Orbscan II topography system. Cornea. 2005;24:259-61.

[34] Hashemi H, KhabazKhoob M, Yazdani K, Mehravaran S, Mohammad K, Fotouhi A. White-to-White Corneal Diameter in the Tehran Eye Study. Cornea. 2010;29:9-12.

[35] Choy EPY, Cho P, Benzie IFF, Choy CKM. Dry eye and blink rate simulation with a pig eye model. Optometry and Vision Science. 2008;85:129-34. 